\title{
PRELIMINARY TECHNICAL ASSESSMENT OF WATER DISTRIBUTION NETWORKS
}

\author{
doc. Ing. Tuhovčák Ladislav, CSc.; Ing. Tauš Miloslav; Ing. Sucháček Tomáš
}

\begin{abstract}
The knowledge of the current technical condition of the operated system is in the interest of the owner or operator of public water supply systems. Such information is the starting point when making decisions on investment projects or planning water mains renewal. The submitted paper introduces the methodology of preliminary assessment of the technical condition of water supply systems and outputs of the software application TEA Water, which makes it possible to assess the technical condition of the specific elements of the water supply systems and clear displaying with the presentation of the assessment results for the entire considered water supply system.
\end{abstract}

Key words: Condition Assessment, Water Supply Systems, Water Network, Water Main

\section{INTRODUCTION}

Assessment of the technical condition is an important part of asset management in terms of quantification and determination of the infrastructure assets performance. Assessment of the technical condition is understood as ,collection of data and information via direct and/or indirect methods followed by the analysis of such data and information in order to identify the current and/or future structural and hydraulic condition and water quality " [5].

To assess the technical condition, we can use direct or indirect methods of assessment. It is advisable to make first a fast efficient assessment of the technical condition and then decide whether further detailed assessment is needed[3]. This opinion advocates the use of indirect methods as the first tool to assess the technical condition due to their lower cost and time demands compared to the direct method costs. Although the indirect methods are unable to provide the necessary level of detail, timeliness and reliability needed to make decisions on the repair and renewal of parts of the system with serious consequences of bursts [5], they may provide valuable information. Indirect assessment methods employ the following types of data [5]:

- $\quad$ Historical data (e.g. pipe age, manufacture, experience with various pipe materials);

- $\quad$ environmental data (e.g. soil conditions, groundwater table, surface load);

- $\quad$ operating data (e.g. flow rate, repairs and maintenance records).

One of the indirect methods is a multi-criteria assessment based on proposed criteria (factors). The burst rate and water supply system deterioration are affected by a number of factors. These factors include operating, environmental and physical characteristics. [4] We can give some examples of factors that influence the technical condition of water supply systems [1]:

- Physical factors - pipe material, wall thickness, year of installation, type of joints, tensile load, external and internal protection of pipes, contact between different metals, pipe production year and manufacturing process;

- Environmental factors - type of soil, soil moisture, presence of ground water, climate, location of pipes in the road, backfill material, pipe bed, underground faults, stray currents, seismic activity, pipe laying method; 
- Operating factors - water pressure, water leaks, water quality, flow rate, operation and maintenance.

The output of the technical condition assessment analysis may take various forms. This could be, for example, engineering calculations, determination of the failure probability, determination of residual service life, marking (scoring) of the condition and/or performance [2]. The most widely used method is probably a scoring scale of the technical condition. As an example of the technical condition we can present the grades used for sewerage in the USA. [2]:

- $\quad$ Grade 1: Asset as new,

- Grade 2: Asset showing initial signs of deterioration,

- Grade 3: Asset condition generally satisfactory (unless in an area of high risk),

- Grade 4: Asset in poor condition; action needed soon (especially in an area of high risk),

- Grade 5: Asset in need of urgent action.

The disadvantage of this grading (categorisation) assessment is that it does provide useful summary information but this entails a significant loss of information [2]. The grading assessments have been designed as screening tools, which means that more information is needed to support the final decision and priority setting, such as risk analyses, cost analyses and operational context analyses. [2]

\section{PROPOSED METHODOLOGY}

The proposed uniform concept of the methodology for the preliminary assessment of the technical condition of water supply system elements is based on the FMEA method. The FMEA (Failure Mode and Effects Analysis) is a method of reliability analysis, which allows for the determination of failures with serious consequences affecting the function of the system and its components. To assess the water supply system based on the FMEA method it is necessary to establish the technical indicators (TI) for the individual subsystems within drinking water supplies. For each indicator we need to define the methods of determination, input data, physical size and presentation method. Based on the technical indicator values the relevant system elements are classified into different categories:

- A (very good) - optimum condition of the relevant indicator, no further measures to change the indicator value are required;

- $\quad$ B (good) - low level of risk of the relevant TI, no principal measures are required;

- $\quad \mathbf{C}$ (average) - these are average values of the relevant TI, no immediate solutions are required;

- D (critical) - Critical values of the relevant indicators. Measures should be planned and implemented to address this situation;

- $\quad \mathbf{E}$ (unacceptable) - undesirable condition requiring immediate solution, if possible, in order to achieve better values of the relevant indicator.

Each category is divided into subcategories - (A-) and $+(\mathrm{A}+)$. This details the evaluation scale.

Compared to the FMEA, this approach has been extended by another level - factors. The technical indicators are currently not assessed directly but their more precise assessment is based on the proposed factors of individual indicators. The relevant element is assessed based on the proposed technical indicators according to table limits of the relevant factors. For each factor there is a table defining the limits of the individual categories. Aggregation is performed sequentially from the lowest 
level using the weighted sum method. The individual elements of water mains are assessed in the following steps:

- $\quad$ Step 1: Grading of the technical indicator factors by the evaluator;

- Step 2: Calculation of the technical indicator assessment of the relevant parts of the element;

- $\quad$ Step 3: Calculation of the assessment of parts of elements, if any;

- $\quad$ Step 4: Calculation of the assessment of the entire water main element.

In the technical condition of the elements of public water supply system is assessed, it is a multicriteria evaluation of alternatives. However, we do not strive to find a single optimal variant (element) but to quantify the technical condition of all the elements. The proposed methodology to assess the technical condition is based on the most common method - the weighted sum method. Other methods may provide better results, however, due to certain subjectivity and uncertainty of the assessed data on this benefit need not be principally important.

In order to capture the assessment of the technical condition of entire water supply systems, the methodology was divided into specific modules according to the structure of the water supply system. The following modules are proposed:

- $\quad$ Module TEAR: water intake structures;

- Module TEAT: water treatment plants,

- $\quad$ Module TEAM: water transmission mains;

- $\quad$ Module TEAA: water towers;

- $\quad$ Module TEAP: pumping stations;

- $\quad$ Module TEAN: water networks;

- Module TEAS: water distribution pipes.

This article introduces in detail the module for the assessment of the technical condition of the water supply system- TEAN and the module for assessing the technical condition of water mains - TEAS.

\section{$2.1 \quad$ Module TEAN}

Module TEAN is used to assess the technical condition of the individual pressure zones or metering districts (DMA). Technical indicators of all modules are divided into a group of structural technical indicators and a group of technological operational indicators. Each indicator is assigned an importance weight in the assessment system. The proposed indicators of the TEAN module are presented in Table 1. For each indicator there are factors that affect the assessment of the relevant indicators and their weights. Based on the assessment of these factors we make the assessment of the individual indicators. 


\begin{tabular}{|l|c|}
\hline Proposed indicators & Weight \\
\hline ST - Structural technical part & $\mathbf{0 , 4 0}$ \\
\hline ST1 - Average pipe material age & 0,50 \\
ST2 - Condition of valves and fittings & 0,40 \\
in the system & 0,10 \\
ST3 - Condition of valve boxes & $\mathbf{0 , 6 0}$ \\
\hline TP - Technological operating part & 0,40 \\
TP1 - Burst rate & 0,25 \\
TP2 - Water losses & 0,25 \\
TP3 - Water quality in the system & 0,10 \\
TP4 - Pressure conditions in the zone
\end{tabular}

Tab. 1 Proposed indicators of TEAN module

\subsection{Module TEAS}

TEAS module is used to assess the individual water mains or pipe sections. The proposed indicators of TEAS module are shown in Tab.2.

\begin{tabular}{|l|c|}
\hline Proposed indicators & Weight \\
\hline ST - Structural technical part & $\mathbf{0 , 5 0}$ \\
ST1 - Age and condition of water main & 0,50 \\
ST2 - Structural technical condition of the & \\
water main & 0,40 \\
ST3 - Main corrosion protection & 0,10 \\
TP - Technological operating part & $\mathbf{0 , 5 0}$ \\
TP1 - Water main burst rate & 0,30 \\
TP2 - Importance of the main in the zone & 0,30 \\
TP3 - Pressure conditions in the main & 0,20 \\
TP4 - Operating indicator & 0,20 \\
\hline
\end{tabular}

Tab. 2 Proposed indicators of TEAS module

\section{CASE STUDIES}

The proposed methodology and also the web software tool TEAWater were tested using both notional and real data of actual water supply systems. Below are presented results of assessing one water supply network (TEAN) and one water distribution pipe (TEAS).

\subsection{Water supply network IFV-N-03 assessment by module TEAN}

This was a pressure zone of the water supply network in a town in South Moravia supplying about 1,500 inhabitants. Despite the considerable age of iron pipes, the pressure zone shows excellent qualities in other indicators. Therefore, the final assessment of the pressure zone water supply network FV-N-03 is graded $\mathbf{B}+$, although there is still a risk of higher age of the laid pipe. 


\begin{tabular}{|c|l|}
\hline Assessment & Structure, parts \\
\hline B+ & TOTAL ASSESSMENT \\
\hline B & ST - Structural technical part \\
4 & ST1 - Average pipe material age \\
1 & $\begin{array}{l}\text { ST2 - Condition of valves and } \\
\text { fittings in the system }\end{array}$ \\
1 & ST3 - Condition of valve boxes \\
\hline A & TP - Technological operating part \\
1 & TP1 - Main burst rate \\
1 & TP2 - Water losses \\
1 & TP3 - Water quality in the system \\
1 & TP4 - Pressure conditions in the zone \\
\hline
\end{tabular}

Tab. 3 Assessment of water supply network FV-N-03 by module TEAN

\subsection{Water supply main FV-S-07 assessment by module TEAS}

This is a water main which is located in the aforementioned pressure zone. Despite the higher age of the main and deteriorated corrosion protection of the cast iron pipes the final rating is still B. However, it may be assumed that in the near future there will be an increase in the burst rate as the water pipe material approaches the end of its theoretical service life.

\begin{tabular}{|c|l|}
\hline Assessment & Structure, parts \\
\hline B & TOTAL ASSESSMENT \\
\hline C & ST - Structural technical part \\
4 & ST1 - Age and condition of water main \\
1 & ST2 - Structural technical condition of water main \\
4 & ST3 - Main corrosion protection \\
\hline A & TP - Technological operating part \\
1 & TP1 - Main burst rate \\
1 & TP2 - Importance of the main in the zone \\
1 & TP3 - Pressure conditions in the main \\
1 & TP4 - Operating indicator \\
\hline
\end{tabular}

Tab. 4 Assessment of water main FV-S-07 by module TEAS

\section{CONCLUSION}

The proposed methodology is the result of the efforts to develop a simple, yet effective methodology for assessing the technical condition of water supply systems. The outputs of this methodology may serve as a basis for comparative analysis, repairs planning, preparation of financial renewal plans required by law concerning water supply and sewerage systems, or as a basis for further detailed structural and technological survey, etc. 
The software tool TEA Water based on proposed methodology can interpret the technical condition of the system under assessment, highlight critical points and rank the operated facilities in an order based on the determined technical condition assessment. Its disadvantage may be the apparent difficulty in obtaining and processing input data and certain subjectivity of the assessment. For more information on the methodology and software tool please visit http://www.teawater.cz.

\section{ACKNOWLEDGEMENT}

This article has been written as part of project no. LO1408 "AdMaS UP - Advanced materials, structures and technologies" supported by the Ministry of Education, Youth and Sports as par of assistance provided within the programme „National Sustainability Programme I" and the specific research project of the Brno University of Technology FAST-S-15-2924 Sensitivity analysis of technical indicators and their weights in assessing the technical condition of public water supply systems.

\section{Literature}

[1] BEST PRACTICES, 2003. Deterioration and inspection of water distribution systems. Best Practice by the National Guide to Sustainable Municipal Infrastructure, Issue No. 1.1, Ottawa.,

[2] MARLOW, D.R., HEART, S., BURN, S., URQUHART, A. and ET AL., 2007. Condition Assessment Strategies and Protocols for Water and Wastewater Utility Assets. WERF, AWWA.

[3] RAHMAN, S. and ZAYED, T., 2009. Condition Assessment of Water Treatment Plant Components. Journal of Performance of Constructed Facilities, 23(4), pp. 276-287.

[4] RAJANI, B. and KLEINER, Y., 2001. Comprehensive review of structural deterioration of water mains: Physically based models. Urban Water, 3(3), pp. 151-164.

[5] U.S.EPA, 2007. Innovation and Research for Water Infrastructure for the 21st Century RESEARCH PLAN.

[6] TUHOVČÁK, L.; KUČERA, T. TAUŠ, M. Technical Audit of Water Supply Systems. In Water Management and Hydraulic Engineering 2015. WATER MANAGEMENT AND HYDRAULIC ENGINEERING. 1. Brno: Institute of Water Structures, FCE, BUT, 2015 s. 245253. ISBN: 978-80-214-5230-5. ISSN: 2410-5910.

[7] TUHOVČÁK, L., KUČERA, T., TAUŠ, M., MENŠÍK. M. TEA Water. In: VODA ZLÍN 2015. 1. Zlín: Tigris, spol s.r.o., 2015, s. 21-24. ISBN 978-80-905716-1-7. 